\title{
Pedro Almodóvar y su influencia en el diseño
}

\author{
Pedro Almodóvar AND HIS INFLUENCE ON DESIGN
}

$\mathrm{Mg}$. Alberto Tassara

Universidad Israel

atassara@uisrael.edu.ec

Fecha de recepción: 08/04/2015

Fecha de aceptación: 26/05/2015

\begin{abstract}
Resumen
Se ha analizado la importancia del cine de Pedro Almodóvar para España e Hispanoamérica. Sin embargo, este director influyó en otras variantes del diseño como el diseño gráfico y, además, ayudó a modificar ciertas formas de pensar. Almodóvar presentó en sus películas una noción del diseño, desde el diseño del vestuario hasta el del set, muy transgresor. Los afiches de sus films siguen la estética del pop.

Resulta muy importante la influencia que tuvo sobre la sociedad. Antes de que fuese reconocido como un inteligente director, incursionó en el mundo de la música. Formó una banda musical y durante los primeros años de la democracia española presentó una serie de temas orientados a la defensa de los derechos de las mujeres y la inserción de los homosexuales. Difundió, en la sociedad española posdictadura, la música pop y el punk como otras tendencias artísticas contra culturales.
\end{abstract}

Palabras clave: Pop, arte, movida madrileña, contra cultura 


\section{Abstract}

It has been analyzed the influence of Pedro Almodóvar's films to Spain and Latin America. However, this filmmaker influenced others areas of the design such as graphic design and also helped to change certain ways of thinking. Regarding to the design, Almodóvar presented in his films a notion of very transgressive design, from costume design to the set. The posters of his films follow the aesthetics of pop.

Almodóvar is very influential on society. Before he was recognized as a smart director, he ventured into the world of music. Formed a musical band and during the early years of the Spanish democracy presented a number of issues that defended the rights of women and the inclusion of homosexuals. He disseminated in Spanish society towards dictatorship pop and punk music and other artistic countercultural trends.

Keywords: Pop art, Madrid scene, counterculture. 


\section{Introducción}

Se ha escrito demasiado sobre Pedro Almodóvar. Resulta curioso, sin embargo, que mientras más se escribe sobre un tema o persona menos se sabe sobre la importancia de dicha persona y sobre la relevancia del tema en cuestión. Se ha dicho mucho sobre este director de cine, pero son pocos los textos que abordan la importancia que tiene en la actualidad sobre el séptimo arte, el diseño gráfico y la cultura.

Este artículo aclarará cómo Pedro Almodóvar cambió la percepción que se tenía sobre la sexualidad, la noción de buen y mal gusto y lo que entendemos por seriedad. No solo se trata de un artista original, estrafalario y provocador sino que sus películas cuestionan la sociedad y especialmente muchos de los prejuicios hispanos. Este artículo intentará mostrar la importancia de Almodóvar en nuestra época.

\section{Desarrollo}

El público español descubre a Pedro Almodóvar durante la década del ochenta. Mujeres al borde de un ataque de nervios, Átame y especialmente Tacones lejanos, donde Miguel Bosé interpreta a un policía que trabaja como drag queen durante la noche, llaman la atención del público. La crítica elogia su estilo, el público joven va a ver estos filmes pero generan rechazo en ambientes tradicionales y en artistas de un gusto clásico e intelectualista.

Ellos le dieron la mala fama de ser un director que busca escandalizar a las buenas conciencias con historias truculentas, pero frívolas. Existe un público que opta por un cine más serio. Se trata de historias falsas, aburridas y que presentan un aura de intelectualidad.

En estos filmes los personajes dialogan interminablemente sobre la libertad o la lucha de clases sociales y terminan por ser una burda parodia de la vida y no su reflejo. Se menciona al cine de Kieslovski y de Godard, con toda malevolencia, como un tipo de filmes de este estilo. Dentro de la cinematografía americana, se puede mencionar el cine de David Lynch.

Almodóvar, por el contrario, recrea la vida con mucha sutileza. Varias de sus historias filman situaciones fantasiosas, con personajes extraños, pero no por ello irreales. Los protagonistas de estas historias experimentan 
nuestras mismas angustias y el mismo conflicto que tenemos al no poder realizar nuestros deseos, algunos de estos sexuales, en el mundo real.

En el polémico filme Matador, que cuenta con la interpretación de Antonio Banderas, se presenta la historia de un muchacho que sueña con ser torero y reprime su despertar sexual por estar reñido con las ideas de una madre conservadora. Paralela a esta historia existe otra, la del profesor de toreo, matador, ex torero, que en su hacienda prepara a los futuros matadores.

El profesor carece de las represiones de su pupilo. Este asesina a sus amantes des- pués de tener relaciones sexuales con ellas, influenciado por una curiosa filosofía taurina que establece una conexión entre el erotismo y el toreo. Ambas historias confluyen al final en un desenlace sorpresivo.

\section{Lo Terrible}

Al igual que en el resto de películas, en esta el director muestra su genialidad al recrear con delicadeza un hecho terrible y hacerlo presentable. Aquí radica la genialidad de Pedro Almodóvar. Hable con ella, que con seguridad es su mejor trabajo, ganador de un globo de oro, se centra en un enfermero muy tímido que cuida a una atractiva muchacha en estado vegetativo.

Él le lee libros todas las noches. Finalmente, la deja embarazada. El talento del director manchego se expresa con genialidad al reflejar un hecho tan reprobable. Por ejemplo, cuando acontece el suceso truculento, se presentan escenas de la historia que el enfermero le cuenta en ese momento, las cuales aluden al acto sexual.

Presentar lo cruel, lo terrible, con sobriedad y sin dramatismo es el logro del director. Escenas similares se pueden ver en Tacones lejanos, que obtuvo un Oscar y un globo de oro, y que indudablemente es una película innovadora.

Estas características lo convierten en un artista genuino. Tiene también otra faceta: la de un cineasta que terminó con muchos prejuicios. Mientras trabajaba en la telefónica, a mediados de los setenta, fue parte de la movida madrileña.

Pedro Almodóvar participó dentro de este movimiento como músico y artista visual.

\section{Almodóvar y la movida madrileña}

La movida madrileña, o movida española, fue un movimiento contracultural similar al de los hippies en Estados Unidos. Se generó durante los últimos años de los setenta e inicios de los ochenta como causa del fin del franquismo. Grupos de jóvenes que se consideraban segregados y criticados por la sociedad española 
empezaron a expresarse sin temor a las represalias. Básicamente eran músicos y tuvieron la ayuda de radios importantes como Radio España, Radio Popular y Radio Juventud. Que el alcalde socialista Enrique Tierno Galván prohibiese la represión de los estudiantes permitió que la juventud se vistiese con colores estridentes, peinados punk y se realizasen conciertos musicales. El libro El miedo a la razón, de este político, analiza este fenómeno social.

Se pueden mencionar músicos pop y punks como Alaska y Dinamarca, Joaquín Sabina y Nacha Pop entre tantos otros. Pedro Almodóvar participó con su grupo Almodóvar y Mcnamara, que lo creó con Fabio Mcnamara, y su primera película Lucy, Pepi y Boon y otras chicas del montón (filme muy criticado) es considerada como un referente del grupo.

Este sería otro rasgo importante de Pedro Almodóvar: un transgresor social. Esa sería, también, una de las razones por las que sus películas han sido tan taquilleras. Las historias de este director muestran una imagen distinta de homosexuales, hippies, rockeros.

Resulta muy curioso ver cómo se satiriza la imagen prototípica del macho hispano que tiene todo bajo control y vuelve locas a las mujeres: tiene esposa, hijos y amante. Lo mismo hace con la mujer dependiente de su esposa o con la feligresa que va a misa todos los días, pero calumnia a vecina, sobrinos, parientes. Se trata de arquetipos de la sociedad hispana, española e hispanoamericana, pero que Almodóvar ridiculiza en todos sus guiones.

La tercera faceta de Pedro Almodóvar es, quizás, la más importante. Se trata de su influencia en el diseño gráfico, de modas y de interiores. Los lugares filmados en estas películas son departamentos y casas de los nuevos ricos españoles que surgieron a finales de los setenta e inicios de los ochenta. Ellos rompieron con el estilo clásico de decorar sus casas y usaron elementos kitsch y pop. Almodóvar no busca burlarse de este estilo ni reivindicarlo, sino que lo usa como un estilo alternativo.

En sus filmes aparecen departamentos de colores estridentes y objetos considerados de mal gusto por una clase tradicional. La psicología y vestimenta de sus personajes suele ser igual de variopinta: punkeros, rockeros y travestis que conviven con personajes tradicionales de España: toreros y opus dei. La forma de vestir, comer o hablar de estos personajes tan opuestos da un tinte especial a las historias.

\section{Conclusiones}

Pedro Almodóvar no constituye solamente un gran director de cine que impuso una forma personal de contar películas. Al mismo tiempo, es un reformador social. Sus historias y la estética que impuso transformaron las costumbres y gustos de los españoles.

España, a pesar de su gran contribución a la cultura española, siempre ha sido desdeñada. Incluso, los franceses decían, con desdén, que Europa termina en los Pirineos. Sin embargo, su aporte al viejo continente y al resto 
del planeta resulta innegable. Un ejemplo es Don Quijote de la Mancha; la primera novela de la humanidad es española. Salvador Dalí y Pablo Picasso revolucionaron la pintura y la forma de decorar interiores. Además, Salvador Dalí fue una influencia importante para el cine.

No se puede saber si Pedro Almodóvar sea un artista de esta importancia. Sin embargo, su influencia salió de España y se convirtió en referente para Francia, donde hay una casa dedicada a estudiar su obra, y ha ganado premios en Inglaterra, Estados Unidos y Alemania. En Hispanoamérica, su influencia es aún más grande. Directores de cine mexicanos y chilenos, principalmente, se han dedicado a seguir sus pasos.

Lo que lo hace un artista reformador de la sociedad es su influencia en la movida madrileña, que como se dijo, supuso una rebelión contra el franquismo, y el ser un referente de los músicos pop de España e Hispanoamérica. 


\section{Bibliografía}

Almodóvar, P. (2015). "Sugerir sin mostrar”. El País, 29 mayo.

Almodóvar, P. (1989). “A veces hay que forzarlo todo, incluso el amor”. La trinchera, 4 de julio.

Argan, G.C. (1992). El arte contemporáneo. Madrid: Akal.

Bourlot, C. (2010). "El movimiento artístico con mayor cercanía con el pueblo". Ensayos sobre la imagen, Revista de la Universidad de Palermo, Buenos Aires.

Creto, J. (1982) Mitologías de la modernidad. Barcelona: Editorial Salvat.

Mapplethorpe, R. (2012). La mirada de Almodóvar. Madrid: La Fábrica Editorial.

Tierno Galván, E. (1986). El miedo a la razón. Tecnos: Madrid. 
